\title{
Application of Optimization Principle in Landmark University Project Selection under Multi-Period Capital Rationing Using Linear and Integer Programming
}

\author{
Nathaniel Kayode Oladejo \\ Department of Physical Sciences, Mathematics Programme, Landmark University, Nigeria \\ Email: Oladejo.nathaniel@lmu.edu.ng
}

How to cite this paper: Oladejo, N.K. (2019) Application of Optimization Principle in Landmark University Project Selection under Multi-Period Capital Rationing Using Linear and Integer Programming. Open Journal of Optimization, 8, 73-82. https://doi.org/10.4236/ojop.2019.83007

Received: March 30, 2019

Accepted: September 1, 2019

Published: September 4, 2019

Copyright $\odot 2019$ by author(s) and Scientific Research Publishing Inc. This work is licensed under the Creative Commons Attribution International License (CC BY 4.0).

http://creativecommons.org/licenses/by/4.0/

\begin{abstract}
The current structure of Landmark University (LU) was induced by raising a generation of solution providers through a qualitative and life-applicable training system that focuses on values and creative knowledge by making it more responsive and relevant to the modern-day demands of demonstration, industrialization and development. The challenge facing Landmark University is the question of which of its numerous projects they should invest to give maximum output with minimum input. In this paper, we maximize the Net Present Value (NPV) and maintain the net discount cash overflow of each project per period as contained and extracted as the secondary data of cash inflows of the Landmark University (LU) monthly financial statement and annual reports from 2012 to 2017 of which the documents have been regrouped as small and large scale projects as many enterprises make more use of the trial-and-error method and as such firms have been finding it difficult in allocating scarce resources in a manner that will ensure profit maximization and/or cost minimization with a simple and accurate decision making by the company through an optimization principle in selecting LU project under multi-period capital rationing using linear programming (LP) and integer programming (IP). The annual net cash flow which is the difference between the cash inflows and cash outflows during each period for the project was estimated and recorded. The discount factors were estimated at cost of capital of $10 \%$ for each cash flow per period with the corresponding NPV at $10 \%$ which revealed that the optimal decision achieves maximum returns of $\$ 110$ $\times 10^{2}$ and this assisted the project manager to select a large number of the variable projects that can maximize the profit which is far better than relying on an ad-hoc judgmental approach to project investment that could have cost
\end{abstract}


$160 \times 10^{2}$ for the same project. Sensitivity analysis on the project parameters are also carried out to test the extent to which project selection is sensitive to changes in the parameters of the system revealed that a little reduction and or addition of reduced cost by certain amount or percentages to its corresponding coefficient in the objective function effect no changes in the shadow prices with solution values for variables $\left(x_{1}\right),\left(x_{4}\right),\left(x_{5}\right)$ and the optimal objective function.

\section{Keywords}

Optimization, Linear, Integer, Programming, Sensitivity, Investment, Maximize, Net Present Value

\section{Introduction}

According to [1], the problem optimizing a factor such as net profit value (NPV) in where resources are limited and funds available over the periods are considered will be recognized as a situation where linear programming and integer programming could be used to solve the problem of which both LP and IP have been used successfully in solving multi-period capital rationing problems. The first Mathematical programming formulation of the multi-period capital rationing (MRC) problem was provided by [2]. In his work, he maximized the net discount cash inflows for the project and maintained the cash inflow and availability of resources in each period and provided a framework using a deterministic linear programming approach. He used Net Present Value (NPV) in the model as an objective function. The values associated with the timing of a part cash flow as adjusted by an appropriate discount rate as opined by [3].

Moreover, [4] examined the application of Optimization principles to optimized parking slot using linear programming in Tamale/Bolgatanga main lorry station at the Tamale Metropolis in the Northern region of Ghana where the maximum parking capacity of the Terminal is examined and fully optimized to avoid traffic congestion in the metropolis and determined the best parking slot allocation to be distributed among different types of vehicle on limited parking space. [5] examined optimization of Landmark Poultry farm products using Simple Linear Programming whereby they investigated and examined the cost invested and as well as cost of producing each poultry farm products and the turn over for the same products in order to find the trend of its' production and predict the possible economics future using Simple Linear programming for an effective decision making in Landmark University poultry farm production.

[6] established optimal principle in solving over-allocation and under-allocation of the classroom space using Linear Programming based on the data obtained from the examination and lecture timetable committee on the classroom facilities, capacities and the number of students per programme to maximize the available classroom space and minimizes the congestion and overcrowding in a 
particular lecture room using AMPL software.

Likewise, [7] applied optimization principle in optimizing profits of a production industry using linear programming where they examined and evaluated production costs to determine the optimal profit using secondary data collected from the records of the Landmark University Bakery on five types of bread produced in the firm where it was revealed through the application of AMPL software that Family loaf and the Chocolate bread contributed objectively to the profit. Hence, more of Family loaf and Chocolate bread are needed to be produced and sold in order to maximize the profit.

In this paper, we develop and formulate Linear and Integer Programming models to solve a multi-period capital rationing (MCR) with divisible and indivisible project problems. The model seeks to produce optimum solution quantities (i.e. total NPV) and the shadow cost (i.e. opportunity cost of building constraints).

\section{Linear Programming}

We consider the following standard form of linear programming:

$$
\begin{aligned}
& \text { Maximize } F=\sum_{j=1}^{n} C_{i} X_{j} \\
& \text { Subject to } \\
& \sum_{j=1}^{n} a(i j) X_{j}=b_{i}, i=1,2, \cdots, n \\
& l_{j} \leq X \leq u_{j}, j=1,2, \cdots, n
\end{aligned}
$$

where $C_{j}$ is the $n$ objective function coefficient, $a(i j)$ and $b$ are parameters in the $m$ linear inequality constraints and $l_{j}$ and $u_{j}$ are lower and upper bounds with $l_{j} \leq u_{j}$. Both $l_{j}$ and $u_{j}$ may be positive or negative.

The specified Linear Programming model for the attainment of the objective function is as follows:

$$
\text { Minimize } Z=\sum C_{j} X_{i}
$$

Subject to

$$
\begin{aligned}
& x_{1}+x_{2}+x_{3}+x_{4}+x_{5}+x_{6}+x_{7}+x_{8}=b_{1} \\
& a_{11} x_{1}+a_{12} x_{2}+a_{13} x_{3}+a_{14} x_{4}+a_{15} x_{5}+a_{16} x_{6}+a_{17} x_{7}+a_{18} x_{8} \leq b_{2} \\
& a_{21} x_{1}+a_{22} x_{2}+a_{23} x_{3}+a_{24} x_{4}+a_{25} x_{5}+a_{26} x_{6}+a_{27} x_{7}+a_{28} x_{8} \leq b_{3} \\
& a_{31} x_{1}+a_{32} x_{2}+a_{33} x_{3}+a_{34} x_{4}+a_{35} x_{5}+a_{36} x_{6}+a_{37} x_{7}+a_{38} x_{8} \leq b_{4} \\
& a_{41} x_{1}+a_{42} x_{2}+a_{43} x_{3}+a_{44} x_{4}+a_{45} x_{5}+a_{46} x_{6}+a_{47} x_{7}+a_{48} x_{8} b_{5} \\
& a_{51} x_{1}+a_{52} x_{2}+a_{53} x_{3}+a_{54} x_{4}+a_{55} x_{5}+a_{56} x_{6}+a_{57} x_{7}+a_{58} x_{8} b_{6} \\
& a_{61} x_{1}+a_{62} x_{2}+a_{63} x_{3}+a_{64} x_{4}+a_{65} x_{5}+a_{66} x_{6}+a_{67} x_{7}+a_{68} x_{8} b_{7} \\
& a_{71} x_{1}+a_{72} x_{2}+a_{73} x_{3}+a_{74} x_{4}+a_{75} x_{5}+a_{76} x_{6}+a_{77} x_{7}+a_{78} x_{8} b_{8} \\
& a_{81} x_{1}+a_{82} x_{2}+a_{83} x_{3}+a_{84} x_{4}+a_{85} x_{5}+a_{86} x_{6}+a_{87} x_{7}+a_{88} x_{8} b_{9} \\
& a_{91} x_{1}+a_{92} x_{2}+a_{93} x_{3}+a_{94} x_{4}+a_{95} x_{5}+a_{96} x_{6}+a_{97} x_{7}+a_{98} x_{8} b_{10} \\
& a_{101} x_{1}+a_{102} x_{2}+a_{103} x_{3}+a_{104} x_{4}+a_{105} x_{5}+a_{106} x_{x}+a_{107} x_{7}+a_{108} x_{8} b_{11} \\
& x_{1} 0, i=1,2,3, \cdots, n
\end{aligned}
$$




\section{Linear and Integer Programming Model for the Project Selection Problem}

In this Linear Programming model, we let $Q_{j}$ be the capital available in LU for investment at time period $t$. Then the problem facing $\mathrm{LU}$ is to determine which project or portion of the project it should initiate with $Q_{j}$. Thus the following algorithms will be strictly follow in determine and solving the challenges.

1) Algorithms for Linear Programming

Step a). Determine the project's NPV using

$$
\beta_{j}(N P V)=\sum_{i=1}^{n}\left[\frac{C_{t}}{(1+r)^{t}}\right]
$$

where $t=0,1 ; j=1,2,3,4,5 \quad C$ is the cash flows

We proposed that the $N P V$ of five (5) projects to be initiated as Agriculture (A) $=\beta_{1}$, Electrification $(\mathrm{B})=\beta_{2}$, Lecture Hall $(\mathrm{C})=\beta_{3}$, Lab. Equipment $(\mathrm{D})=$ $\beta_{4}$, Staff/Student Quarters $(\mathrm{E})=\beta_{5}$.

Step b). Formulate the Linear Programming problems by defining the objective functions, decision variables and the constraints.

Thus:

$$
\begin{aligned}
& \text { Maximize } Z \\
& =\beta_{1} X_{A}+\beta_{2} X_{B}+\beta_{3} X_{C}+\beta_{4} X_{D}+\beta_{5} X_{E}
\end{aligned}
$$

While the decision variables $\left(X_{j}\right)$ are characterized as follows

$X_{A}$ is the proportion of project A to be initiated when $j=1$

$X_{B}$ is the proportion of project B to be initiated when $j=2$

$X_{C}$ is the proportion of project $\mathrm{C}$ to be initiated when $j=3$

$X_{D}$ is the proportion of project $\mathrm{D}$ to be initiated when $j=4$

$X_{E}$ is the proportion of project E to be initiated when $j=5$

2) Algorithms for Integer Programming for the project selection problem

For $Q_{j}$ be the capital available in $\mathrm{LU}$ for investment at time period $t$ and the problem facing $\mathrm{LU}$ is to determine which project or portion of the project it should initiate with $Q_{j}$. Thus LU must take into consideration that:

a) It cannot invest in all $N$ projects suitable for investment which run for $n$ year.

b) The project characteristics show that $\sum_{i} d_{(i, j)}$ is greater than $R_{j}$ where $d_{(i, j)}$ is the least requirement for $j$ projects and $R_{j}$ is the capital for investment.

c) All the projects and the constraints are independent on one another.

d) Equal investment opportunities are assumed for the project for each period.

e) The cash flows, resources and constraints are well known.

Our main decision problem is to determine which project the LU should select in order to maximize the total returns. To formulate this Integer Programming, we follow these algorithms:

Step i). Define the decision variable as follows 
Let $X_{j}=\left\{\begin{array}{l}1, \text { if } \mathrm{LU} \text { invest in project } j \\ 0, \text { if LU does not invest in project } j\end{array}\right.$

$$
j=1,2, \cdots, n
$$

where $X_{j}$ are integer variable which takes one of two possible values $(0,1)$ and represents a binary decision.

Step ii). Define the constraints as follows

We let $d_{(i, j)}$ be the capital requirement for $j$ project, $R_{j}$ be available capital for $j$ project for each year.

$$
\sum_{j=1}^{N} d(i, j) X_{j} \leq R_{i} \text { for } j=1,2, \cdots, N ; i=1,2, \cdots, m
$$

Then the constraints relating to availability of capital funds each year are:

Step. iii) Objective function.

We let the total profit be

$$
\sum_{j=1}^{N} P_{j} X_{j}
$$

Maximize

$$
Z=\sum_{j=1}^{N} P_{j} X_{j}
$$

Subject to

$$
\sum_{j=1}^{N} d(i, j) X_{j} \leq R_{j}
$$

\section{Mathematical Model of Project Selection under Multi-Period Capital Rationing}

Since the problem facing $\mathrm{LU}$ is to determine which project or portion of the project, it should initiate with $Q_{j}$ and subject to these constraints, they were faced with budgetary limitation. Thus

1) For the capital project at the initial time $(t)=0$,

$$
a_{(1,1)} X_{A}+a_{(1,2)} X_{B}+a_{(1,3)} X_{C}+a_{(1,4)} X_{D}+a_{(1,5)} X_{E} \leq Q_{1}
$$

2) For the capital project at the take up time $(t)=1$,

$$
a_{(2,1)} X_{A}+a_{(2,2)} X_{B}+a_{(2,3)} X_{C}+a_{(2,4)} X_{D}+a_{(2,5)} X_{E} \leq Q_{2}
$$

3) Then we specified the following proportion constraints to ensure that a project is not accepted more than once or negative projects are not accepted:

$$
\begin{aligned}
& X_{A}, X_{B}, X_{C}, X_{D}, X_{E} \leq 1 \\
& X_{A}, X_{B}, X_{C}, X_{D}, X_{E} \leq 0
\end{aligned}
$$

where $a_{(i, j)}$ are cash flows for each period and for each project.

We then transform the formula into the compact form as:

Maximize $Z=\beta_{1} X_{1}+\beta_{2} X_{2}+\beta_{3} X_{3}+\beta_{4} X_{4}+\beta_{5} X_{5}$ 
Subject to:

$$
\begin{aligned}
& a_{(1,1)} X_{1}+a_{(1,2)} X_{2}+a_{(1,3)} X_{3}+a_{(1,4)} X_{4}+a_{(1,5)} X_{5} \leq Q_{1} \\
& a_{(2,1)} X_{1}+a_{(2,2)} X_{2}+a_{(2,3)} X_{3}+a_{(2,4)} X_{4}+a_{(1,5)} X_{5} \leq Q_{2} \\
& X_{1} \quad \leq 1 \\
& X_{2} \\
& X_{3} \quad \leq 1 \\
& \begin{array}{ll}
X_{4} & \leq 1
\end{array} \\
& X_{5} \leq 1 \\
& a_{(1,1)} X_{1}+a_{(1,2)} X_{2}+a_{(1,3)} X_{3}+a_{(1,4)} X_{4}+a_{(1,5)} X_{5} \leq Q_{1} \\
& a_{(2,1)} X_{1}+a_{(2,2)} X_{2}+a_{(2,3)} X_{3}+a_{(2,4)} X_{4}+a_{(1,5)} X_{5} \leq Q_{2} \\
& X_{1} \\
& X_{2} \\
& \leq 0 \\
& \leq 0 \\
& X_{3}
\end{aligned}
$$

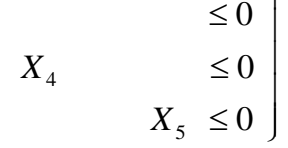

Generally, we then have the following form of equation:

$$
\left.\begin{array}{ll} 
& \text { Maximize } Z=\sum_{j=1}^{N} B_{j} X_{j} \\
\text { Subject to } & \sum_{j=1}^{N} a(i, j) X_{j}=Q_{i} \\
& 0 \leq X_{j} \leq 1, i=1,2, \cdots, m ; j=1,2, \cdots, n
\end{array}\right\}
$$

where $\left(a_{(i, j)}, Q_{j}, \beta_{j}\right)$ are given and $n$ is the number of the projects to be invested and $Z$ constitutes the objective function.

\subsection{Implementation of LP and IP Models in LU Project Selection}

\subsubsection{Sources and Data Collection}

Information about cash inflows of the LU small and capital projects with distribution of capital requirements for the Small Project from 2012-2017 as shown in Table 1 and Table 2 below were extracted from the LU financial statement, monthly and annual report from 2012 to 2017. The LU project were classified into small and capital project and the discount factors were estimated at cost of capital of $10 \%$ for each cash flow for each period and the corresponding NPV at 10\%. While Table 3 below shows the results for the above LP model for large scale using MATLAB Package.

\subsubsection{LP Model Implementation}

From Equations (7) and (8) we applied LP model to LU capital rationing data in Table 1 and formulate $\mathrm{LU}$ project selection problem as shown below.

$$
\left.\begin{array}{ll}
\text { Maximize } & Z=\sum_{j=1}^{N} B_{j} X_{j} \\
\text { Subject to } & \sum_{j=1}^{N} a(i, j) X_{j}=Q_{i} \\
& 0 \leq X_{j} \leq 1, i=1,2, \cdots, M ; j=1,2, \cdots, N
\end{array}\right\}
$$


Table 1. The net cash flow of LU Large scale project for 2012-2017.

\begin{tabular}{ccccccccc}
\hline Year & 2012 & 2013 & 2014 & 2015 & 2016 & 2017 & & P.1 \\
Project period & 0 & 1 & 2 & 3 & 4 & 5 & & \\
\hline Agriculture $\left(x_{1}\right)$ & 100 & 100 & 200 & 400 & 600 & 500 & 264 & 0.83 \\
Electrification $\left(x_{2}\right)$ & 400 & 500 & 1000 & 1200 & 1400 & 1200 & 719 & 0.80 \\
Lecture hall $\left(x_{3}\right)$ & 250 & 200 & 360 & 500 & 400 & 0 & 237 & 0.92 \\
Lab. equipment $\left(x_{4}\right)$ & 30 & 50 & 60 & 60 & 150 & 90 & 217 & 0.33 \\
Staff/std quarters $\left(x_{5}\right)$ & 10 & 20 & 10 & 0 & 30 & 50 & 72 & 0.72 \\
Discount factors & 1.00 & 0.909 & 0.826 & 0.751 & 0.683 & 0.621 & & \\
Capital Limitation $Q_{1}$ & 550 & 500 & 450 & 400 & 650 & 700 & & \\
\hline
\end{tabular}

Table 2. The distribution of capital requirement for Small Project for 2012-2017.

\begin{tabular}{cccccccc}
\hline Year & 2012 & 2013 & 2014 & 2015 & 2016 & 2017 & Capital \\
Project period & 0 & 1 & 2 & 3 & 4 & 5 & returns \\
\hline Machineries $\left(x_{1}\right)$ & 50 & 30 & 20 & 60 & 40 & 20 & 50 \\
Refuse facility $\left(x_{2}\right)$ & 10 & 80 & 20 & 20 & 30 & 60 & 30 \\
Borehole water $\left(x_{3}\right)$ & 15 & 15 & 30 & 40 & 60 & 0 & 50 \\
Shield $\left(x_{4}\right)$ & 10 & 40 & 10 & 10 & 0 & 10 & 10 \\
Bus stop $\left(x_{5}\right)$ & 10 & 0 & 10 & 20 & 50 & 10 & 20 \\
Available capital & 80 & 145 & 90 & 100 & 165 & 80 & \\
\hline
\end{tabular}

Table 3. The results for the above LP model for large scale using MATLAB Package. Optimal solution (Max objective function) $=\$ 1027.56 \times 10^{2}$.

\begin{tabular}{cccccc}
\hline Decision variables & $\begin{array}{c}\text { Solution } \\
\text { variables }\end{array}$ & $\begin{array}{c}\text { Unit cost } \\
\text { or profit }\end{array}$ & $\begin{array}{c}\text { Total } \\
\text { contribution }\end{array}$ & $\begin{array}{c}\text { Shadow } \\
\text { price }\end{array}$ & $\begin{array}{c}\text { Reduction } \\
\text { cost }\end{array}$ \\
\hline Agriculture $\left(x_{1}\right)$ & 1.00 & 264 & 264 & 0 & 0 \\
Electrification $\left(x_{2}\right)$ & 0.662 & 719 & 474.56 & 1.438 & 0 \\
Lecture hall $\left(x_{3}\right)$ & 0 & 237 & 0 & 0 & 0.6 \\
Lab. equipment $\left(x_{4}\right)$ & 1.00 & 217 & 217 & 0 & 0 \\
Staff/Std. quarters $\left(x_{5}\right)$ & 1.00 & 72 & 72 & 0 & 0 \\
Pmax. & & 1,509 & $1,027.56$ & & \\
\hline
\end{tabular}

Thus we have:

Maximize $Z=264 X_{1}+719 X_{2}+237 X_{3}+217 X_{4}+72 X_{5}$

Subject to $100 X_{1}+400 X_{2}+250 X_{3}+30 X_{4}+10 X_{5} \leq 550$

$100 X_{1}+500 X_{2}+200 X_{3}+50 X_{4}+20 X_{5} \leq 500$

$200 X_{1}+1000 X_{2}+360 X_{3}+60 X_{4}+10 X_{5} \leq 450$

$400 X_{1}+1200 X_{2}+500 X_{3}+60 X_{4} \leq 400$

$600 X_{1}+1400 X_{2}+400 X_{3}+150 X_{4}+30 X_{5} \leq 650$ 
$500 X_{1}+1200 X_{2}+90 X_{4}+50 X_{5} \leq 700$

$0 \leq X_{j} \leq 1, j=1,2,3,4,5$

\subsubsection{Sensitivity Analysis for Linear Programming}

Here the stability or robustness of the model is tested by a slight change in the technological coefficients in order to determine the redundancy or otherwise of one of the constraints, this helps make better recommendations and reduce errors in making decisions. The redundancy of a constraint is also put into test and the solution compared to the original LP problem as shown in Table 4 below by the reduced cost of 50.6 in row $\left(x_{3}\right)$ shows the amount by which the objective function coefficient for the variable $\left(x_{3}\right)$ should be change to make it a non-zero. Hence the coefficient of $\left(x_{1}\right)$ in the objective function is altered by -50.6 and the LP problem will be resolved to yield.

\subsubsection{Interpretation of Results for Sensitivity}

Addition of the reduced cost of 50.6 on the row of variable $\left(x_{2}\right)$ to its corresponding coefficient in the objective function effect no changes in the shadow prices with solution values for variables $\left(x_{1}\right),\left(x_{4}\right),\left(x_{5}\right)$ and the optimal objective function. However, there were sharp variations in some optimal solution values. The coefficient of variables $\left(x_{2}\right)$ decreased from 0.662 to 0.38042 while $\left(x_{3}\right)$ increases from 0 to 0.69895 , increasing the NPV per unit on variable $\left(x_{3}\right)$, impact a sharp change on the optimal solution. Given the sensitivity analysis of one or more of the key factors of project like this, the LU management's task is to decide whether the project is commendable and worthwhile.

\section{Integer Programming Model Implementation}

From Table 2, we put LU small scale project selection problem data into the IP model as:

$$
\begin{aligned}
& \text { Maximize } Z=\sum_{j=1}^{N} P_{j} X_{j} \\
& \text { Subject to } \sum_{j=1}^{N} d_{(i, j)} X_{j} \leq R_{j}, X_{j}=0 ; j=1,2, \cdots, N \\
& 0 \leq X_{j} \leq 1, i=1,2, \cdots, m ; j=1,2, \cdots, n \\
& \text { Thus: } \\
& \text { Maximize } Z=50 X_{1}+30 X_{2}+50 X_{3}+10 X_{4}+20 X_{5} \\
& \text { Subject to } 50 X_{1}+10 X_{2}+15 X_{3}+10 X_{4}+10 X_{5} \leq 80 \\
& X_{1}+80 X_{2}+15 X_{3}+40 X_{4}+0 X_{5} \leq 145 \\
& 20 X_{1}+20 X_{2}+30 X_{3}+10 X_{4}+10 X_{5} \leq 90 \\
& 20 X_{1}+20 X_{2}+40 X_{3}+10 X_{4}+20 X_{5} \leq 100 \\
& 60 X_{1}+30 X_{2}+60 X_{3}+0 X_{4}+50 X_{5} \leq 145 \\
& 40 X_{1}+60 X_{2}+0 X_{3}+0 X_{4}+10 X_{5} \leq 80 \\
& X_{j}=0 \text { or } 1, j=1,2,3,4,5
\end{aligned}
$$

The above LP was solved using MATLAB and the results of the binary decision are shown in Table 5 below. 
Table 4. The sensitivity analysis of the Large Scale project. Optimal solution (Max. objective function) $=\$ 1027.72$.

\begin{tabular}{cccccc}
\hline $\begin{array}{c}\text { Decision } \\
\text { variables }\end{array}$ & $\begin{array}{c}\text { Solution } \\
\text { variables }\end{array}$ & $\begin{array}{c}\text { Unit cost } \\
\text { or profit }\end{array}$ & $\begin{array}{c}\text { Total } \\
\text { contribution }\end{array}$ & $\begin{array}{c}\text { Shadow } \\
\text { price }\end{array}$ & $\begin{array}{c}\text { Reduction } \\
\text { cost }\end{array}$ \\
\hline Agriculture $\left(x_{1}\right)$ & 1.00000 & 264 & 264 & 0 & 0 \\
Electrification $\left(x_{2}\right)$ & 0.38042 & 719 & 273.52 & 1.438 & 0 \\
Lecture hall $\left(x_{3}\right)$ & 0.69895 & 287.6 & 201.20 & 0 & 0 \\
Lab. equipment $\left(x_{4}\right)$ & 1.00000 & 217 & 217 & 0 & 0 \\
Staff/Std. quarters $\left(x_{5}\right)$ & 1.00000 & 72 & 72 & 0 & 0 \\
Pmax. & & & $1,027.72$ & & \\
\hline
\end{tabular}

Table 5. Optimal objective function value $=110 \times 10^{2}$.

\begin{tabular}{ccccc}
\hline $\begin{array}{c}\text { Decision } \\
\text { variables }\end{array}$ & $\begin{array}{c}\text { Solution } \\
\text { variables }\end{array}$ & $\begin{array}{c}\text { Unit cost } \\
\text { or profit }\end{array}$ & $\begin{array}{c}\text { Total } \\
\text { contribution }\end{array}$ & $\begin{array}{c}\text { Reduction } \\
\text { cost }\end{array}$ \\
\hline Machineries $\left(x_{1}\right)$ & 1 & 50 & 50 & 0 \\
Refuse facility $\left(x_{2}\right)$ & 0 & 30 & 0 & 30 \\
Borehole water $\left(x_{3}\right)$ & 1 & 50 & 50 & 0 \\
Shield $\left(x_{4}\right)$ & 1 & 10 & 10 & 0 \\
Bus stop $\left(x_{5}\right)$ & 0 & 20 & 0 & 20 \\
Pmax. & & 160 & 110 & \\
\hline
\end{tabular}

\section{Interpretation of IP Results}

The optimal decision is to choose $\left(x_{1}\right),\left(x_{3}\right),\left(x_{4}\right)$, while LU can provide $\left(x_{2}\right),\left(x_{5}\right)$ with $n$ capital for the next five years unless the LU investment is reviewed. The optimal decision achieves maximum returns of $110 \times 10^{2}$. It is evident that the model has assisted the project manager to select a large number of the variable projects that can maximize profit. This is larger than relying on an ad-hoc judgmental approach to project investment that could have cost $160 \times 10^{2}$ for the same project.

\section{Conclusions}

In this paper we have successfully examined optimization principles and its applications in selecting potential projects in $\mathrm{LU}$ in order to maximize the returns and the profits from the batch of projects by maximizing the Net present Value (NPV) and maintain the net discount cash overflow for each project per period as contained in data collected from LU monthly financial statement and annual report from 2011 to 2016 revealed that LU will incur $1509 \times 10^{2}$ as unit cost or profit for a total contribution of $1027.56 \times 10^{2}$.

The discount factors were estimated at cost of capital of $10 \%$ for each cash flow per period with the corresponding NPV at $10 \%$ which revealed that the optimal decision achieves maximum returns of $\$ 110 \times 10^{2}$ and this will help the project manager to select a large number of the variable projects that can maximize the profits which is far better than relying on an ad-hoc judgmental ap- 
proach to project investment that could have cost $160 \times 10^{2}$ for the same project.

Sensitivity analysis on the project parameters revealed that a little reduction and/or addition of reduced cost by certain amount or percentages to its corresponding coefficient in the objective function effect changes in the shadow prices with solution values for variables $\left(x_{1}\right),\left(x_{4}\right),\left(x_{5}\right)$ and the optimal objective function. However, there were sharp variations in some optimal solution values where the coefficient of variables $\left(x_{2}\right)$ decreased while $\left(x_{3}\right)$ increased and an increase in NPV per unit on variable $\left(x_{3}\right)$, has a sharp change on the optimal solution.

This will give some guidance to the firm management in their consideration of many options with regards to the limited resources and for the decision-making process.

\section{Conflicts of Interest}

The author declares no conflicts of interest regarding the publication of this paper.

\section{References}

[1] Powel, C.G. (1998) Theory of Linear and Integer Programming. John Willey \& Sons, New York. https://pdfs.semanticscholar.org/3ce2/d233cee585ecff73729836918ba87195c18f.pdf

[2] Weingartner, H.M. (1963) Mathematical Programming and the Analysis of Capital Budgeting Problems. Prentice Hall, Englewood Cliffs, New Jersey. https://archive.org/details/mathematicalprog00wein

[3] Samuel, O.O., Olusegun, A.O., Adebimpe, O.A. and Akinbowale, T.T. (2015) Optimized Nutrients Diet Formulation of Broiler Poultry Rations in Nigeria Using Linear Programming. Journal of Nutrition and Food Sciences, S14, 1-6. https://doi.org/10.4172/2155-9600.S14-002

[4] Oladejo, N.K. and Awuley, B.D. (2016) Application of Linear Programming in Optimization of Parking Slot: A Case Study of Tamale-Bolgatanga Lorry Station in Ghana. International Journal of Emerging Technology and Advanced Engineering, 6, 147-154. https://eprints.lmu.edu.ng/1369/1/IJETAE_1116_23.pdf

[5] Oladejo, N.K., Godwin, A., Okoro, J.O. and Abukari, H.I. (2017) Optimization of Landmark Poultry Farm Product Using Simple Linear Programming. Journal of Mathematics, 13, 43-49. http://www.iosrjournals.org/iosr-jm/papers/Vol13-issue4/Version-3/G1304034349.pdf

[6] Oladejo, N.K., Abolarinwa, A., Salawu, S.O., Lukman, A.F. and Bukari, H.I. (2019) Optimization Principles and Its' Application in Optimizing Landmark University Bakery Production Using Linear Programming. International Journal of Civil Engineering and Technology, 10, 183-190. http://www.iaeme.com/ijciet/IJCIET_Paper.asp?sno=15790

[7] Oladejo, N.K., Abolarinwa, A., Salawu, S.O., Lukman, A.F. and Bukari, H.I. (2019) Application of Optimization Principles in Classroom Allocation Using Linear Programming. International Journal of Mechanical Engineering and Technology, 10, 874-885. http://eprints.lmu.edu.ng/2145/1/IJMET_10_01_091.pdf 